\title{
REFLECTIVE LEARNING IN BUSINESS EDUCATION: A REPLICATION IN AN ASIAN CONTEXT
}

\author{
Weiling Zhuang, Eastern Kentucky University, USA \\ Pinghui Zhu, Xiamen University, China \\ Maxwell K. Hsu, University of Wisconsin- Whitewater, USA \\ Qian Xiao, West Texas A\& M University, USA
}

\begin{abstract}
Reflective learning has been examined in recent years by researchers across various disciplines including marketing education (Peltier, Hay, and Drago 2005), leadership development (Densten and Gray 2001), human resource development (Corley and Eades 2004), and health sciences (Kember et al. 2000). Reflection in the learning process is an important human activity in which people engage their experiences and discover insights in order to lead to a new understanding and application (Boud et al., 1985).

Although reflective learning has received substantial attention in other disciplines, there are scant works of this concept in the marketing and business literature (Catterall et al. 2002). In the present study, we sought to replicate the findings reported in Peltier, Hay, and Drago's $(2005,2006)$ work with an ethnically different sample of Chinese MBA students.

The empirical results provide partial support for Peltier, Hay, and Drago's $(2005,2006)$ studies. First, the results of the regression model for reflection dimensions (RMRD) model confirm Peltier, Hay, and Drago's findings that the higher levels of reflection learning (e.g., intensive reflection, reflection, deep understanding, and deep processing) positively enhance students' learning experience. These higher levels of the reflection learning continuum are more associated with deeper learner and learning traits (e.g., Mezirow 1991). The results suggest that these deeper learning activities help students in appraising their experience, challenging the existing assumption, identifying alternative solutions to problems, and motivating better responses. In contrast, the relative passive learning activities such as habitual action and basic understanding focus on the surface learning portion of reflective learning (Peltier, Hay, and Drago 2006). These lower levels of reflective learning require activities such as learning through repetition, routine thinking, memorizing rather than critical thinking, and superficial understanding. The results indicate that these lower levels of reflective learning are negatively related to learning experience although the relationships are not significant.
\end{abstract}

In conclusion, this study delineates the complexity of the reflective learning continuum using a Chinese MBA student sample. The results yielded by this study and its predecessors suggest: (1) reflective learning is a multiple-dimensions concept, (2) different dimensions of reflective learning show different impacts on students' learning performance, and (3) the effects of reflective learning should be tested across different social and cultural contexts. The present study suggests that more work needs to be conducted to examine the validity and reliability of measures of reflective learning.

References are available upon request. 